Tạp chi Khoa học và Công nghệ, Số 30, 2017

\title{
GALLOPING INSTABILITY ANALYSIS OF A CABLE-DAMPER SYSTEM
}

\author{
NGUYEN HUY CUNG, DO CAO PHAN \\ Department of Civil Engineering, Industrial University of Ho Chi Minh City; \\ nguyenhuycung@iuh.edu.vn,docaophan@iuh.edu.vn
}

\begin{abstract}
Viscous dampers are used widely to mitigate cable vibrations cable-stayed bridges. A damper attached to a stay cable leads to complex modes. The complexity can highly affect the aeroelastic stability of the cable. A galloping instability analysis of cable with an attached damper will be presented. A numerical example points out errors of conventional galloping analysis. The complexity of the mode shapes leads the cable being more unstable than ignoring it by treating the mode shapes as real.

Keywords. cable, cable-stayed bridge, complex modes, galloping, viscous damper.
\end{abstract}

\section{INTRODUCTION}

A stay cable, such as a member of a cable-stayed bridge, is vulnerable to large vibration as its inherent damping is very low. A solution widely used in practice to dampen its vibration is to install a viscous damper transversely to the cable near the cable anchorage. Such a damper is designed through a damping coefficient such that it can be optimally tuned for maximum damping ratio of one targeted mode of vibration. Many investigations, e.g. [1-6], have been proposed to understand the natural dynamic properties of a cable with an attached viscous damper in free vibration and then to design an optimal damper. Meanwhile, based on the authors' knowledge, its dynamic behaviour under wind action has never been discussed. This is an important issue as cables are very susceptible to wind, and cable-wind interaction is the main cause of the violent vibration of cables which can result in galloping instability [7-8].

In the efforts to find the damping properties of the cable-damper system, free vibration has been analysed to solve the eigenvalue problem, in which the cable is usually modelled as a taut string. The first study is credited to Carne [1]. He formulated the complex eigenvalue problem and provided an approximate solution through a numerical procedure. The damping ratio of the first mode was then given. Subsequently, used a numerical approach was used to identify the optimal modal damping which depends on the distance between the damper and the cable anchorage [2-3]. Later, the Galerkin method was applied to estimate the complex frequencies of the cable-damper system and then introduced a universal curve which links the normalized modal damping ratio of the cable with the normalized damping coefficient of the attached damper [4]. The universal curve provided a very efficient tool for the design of the damper. This curve was then formulated analytically in [5], in which the asymptotical solution for the free vibration of the cabledamper system was derived.

As no study on galloping instability of a cable-damper system is available to date, the galloping condition is evaluated by using conventional methods present in literature. The most used method in practice for this issue is the Glauert-Den Hartog criterion, in which the structure is prone to galloping in the across-wind direction when the aerodynamic damping is negative [9-10]. By including the effect of Reynolds number and relative angle between wind and structure, the generalised across-wind galloping condition was developed and applied to cables [11]. Taking into account the inherent coupling between along-wind and across-wind vibrations, the galloping condition was derived for a two degree-of-freedom (2DOF) system when the two fundamental natural frequencies associated with along-wind and across-wind directions are identical (the resonant condition) [12]. Applied to a variety of typical shapes of ice-accreted cables, such a study emphasized the importance of the effect of the coupling between along-wind and across-wind effects. The coupled translational galloping phenomenon studied in [12] was explained qualitatively with perturbation solutions for the resonant and non-resonant conditions [13]. The 2DOF galloping problem for yawed cylinders which have arbitrary attitudes with respect to the wind was generalized in [14] and [15]. Especially, the later provided analytical formula for the damping necessary to be added to a prismatic structure to prevent the occurrence of galloping in the general condition. Recently, a general criterion has been developed for the coupled translational galloping condition for slender 
structures with generic cross-sections, taking into account structural eccentricities, modes shapes, higher modes and the variation of mass, width of cross-section and aerodynamic coefficients along the structure, which have not been included in previous studies, [16].

It is important to note that to analyse the galloping instability conditions of a stay cable with an attached damper, the methods mentioned above have be applied. Among them, the Glauert-Den Hartog criterion has been mostly used in practice thanks to its simplicity. Also, the modes shapes in the cabledamper plane are treated as the same as those in the orthogonal cable plane. Allowing the aeroelastic coupling between the planes, this results in the 2DOF resonant condition for the occurrence of galloping being independent from the mode shapes for the uniform cables [15]. However, these approaches may incorrectly predict the galloping condition as they did not consider the complexity of the frequencies and modes shapes which is a significant characteristic of a cable-damper system.

In response to this challenge, Nguyen and Macdonald developed a theoretical framework for galloping instability of a stay cable with an attached viscous damper [17]. The theory takes into account the complex modes, and the variation of mass, width of cross-section and aerodynamic coefficients along the structure. Based on such a theory, this paper aims to analyse the stability of a real cable with an attached damper. In the paper's organization, Section 2 summarizes the theory of galloping analysis of a cable-damper system, developed in [17]. Section 3 presents an application of the theory to a real cable accreted by ice. Finally, Section 4 draws conclusions.

\section{GALLOPING ANALYSIS OF CABLE-DAMPER SYSTEM}

Consider a stay cable, neglecting sag, with length Lin a Cartesian coordinate system $x y z$ as illustrated in Fig. 1, in which $z$ is along the cable axis while $y$ and $x$ are translational principal axes corresponding to the in-plane and out-of-plane of the cable. For simplicity, the in-plane and out-of-plane are denoted as $y$ plane and $x$-plane, respectively.

In the $\alpha$-plane $(\alpha=x, y)$, a viscous damper with damping coefficients c $\alpha$ is attached to the cable at $z=\mathrm{d}$. To describe the motion of a taut cable with one or two attached dampers, it is more general to consider two dampers attached to the cable. If there is only one, for example in the $x$-plane, then $c_{y}=0$.

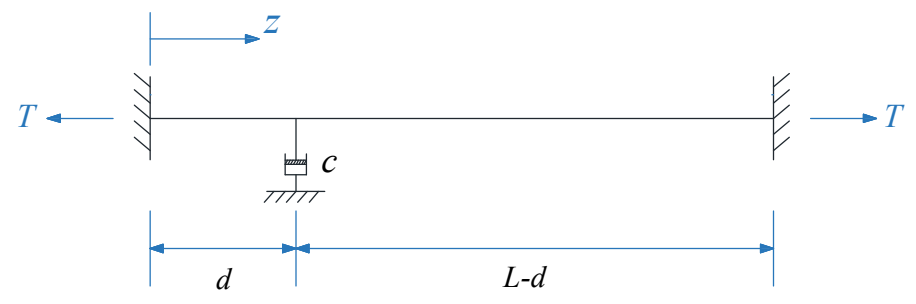

Figure 1. A taut cable with an attached viscous damper.

The equation of motion of a taut cable with an attached viscous damper is usually formulated by modifying the equation of motion of an undamped taut string with the addition of the damping force to the external force and neglecting any inherent damping of the cable. The equation of motion in the cable damper plane is expressed as [4]:

$$
m(z) \ddot{q}(z, t)+\mathrm{D} \dot{q}(z, t)+\mathrm{K}[q(z, t)]=f(z, t)
$$

where $m(z)$ is the mass per unit length; $q(z, t)$ is the displacement; dot stands for time derivative; $\mathrm{K}=-\frac{T \partial^{2}}{\partial z^{2}}$ is a spatially differential stiffness operator; $T$ is the tension force; $f(z, t)$ is the external force; $\mathrm{D}=c \delta(z-$ d), beingcis the damping coefficient.

The boundary conditions are given by:

$$
\begin{gathered}
q(0, t)=q(L, t)=0 \text { and } \dot{q}(0, t)=\dot{q}(L, t)=0 \\
T\left[q^{\prime}\left(d^{+}, t\right)-q^{\prime}\left(d^{-}, t\right)\right]=c \dot{q}(d, t)
\end{gathered}
$$

where the prime denotes the spatial derivative. 
The mode shape of the whole cable is expressed in a single function as:

$$
\phi_{n}(z)=\phi_{n}(d)\left\{\psi_{n}(z, d)+\left[\psi_{n}(L-z, L-d)-\psi_{n}(z, d)\right] \mathcal{H}(z-d)\right\}
$$

where $\mathcal{H}(z-d)$ is the Heaviside function and $\psi_{n}(z, d)$ is given by:

$$
\psi_{n}(z, d)=\frac{\sin \left(\beta_{n} z\right)}{\sin \left(\beta_{n} d\right)}
$$

where $n$ is the mode number; $\beta_{n}$ is the $n^{\text {th }}$ wave number, related to the nth eigenvalue $\lambda_{n}$ of the system governed by Eq. (1) by $\beta_{n}=-i \lambda_{n} \sqrt{\frac{m}{T}}$, being $i$ the imaginary number. At this moment, $\lambda_{n}$ is still unknown and will be discussed later.

To evaluate the response or stability of the cable-damper system, it is necessary to decouple Eq.(1) in SDOF system. Extending the modal decomposition method presented in the standard textbook [18] for a MDOF system to a continuous system, it is possible to decouple the equation of motion in the following forms:

$$
\dot{p}_{n}(t)-\lambda_{n} p_{n}(t)=\frac{1}{w_{n}} f_{n}(t) ; n=1,2,3, \ldots
$$

where $p_{n}(t)$ are modal coordinates; the overbar denotes the complex conjugate, and

$$
\begin{gathered}
w_{n}=\int_{0}^{L}\left[\boldsymbol{\Psi}_{\mathrm{n}}(z)\right]^{T}\left[\begin{array}{cc}
0 & m \\
m & \mathrm{D}
\end{array}\right] \boldsymbol{\Psi}_{\mathrm{n}}(z) d z \text { and } \boldsymbol{\Psi}_{\mathrm{n}, \alpha}(z)=\left[\begin{array}{ll}
\lambda_{n} \phi_{n}(z) & \phi_{n}(z)
\end{array}\right]^{T} \\
f_{n}(t)=\int_{0}^{L}\left[\boldsymbol{\Psi}_{\mathrm{n}}(z)\right]^{T} \mathbf{f}(z, t) d z \text { and } \mathbf{f}(z, t) d z=\left[\begin{array}{ll}
0 & f(z, t)
\end{array}\right]^{T}
\end{gathered}
$$

Finally, the solutions of Eqs. (6) can be found when the eigenvalues $\lambda_{n, \alpha}$ are known. Generally, they can be determined numerically. For a special case that the damper is close to the anchorage, i.e. $d<<L$, the asymptotic solutions are given by [5]:

$$
\lambda_{n}=i\left[n \pi+\frac{i \eta\left(\kappa_{n}\right)^{2}}{1+i \eta \kappa_{n}}\right] \frac{1}{L} \sqrt{\frac{T}{m}}
$$

where $\eta=\frac{c}{\sqrt{T m}}$ and $\kappa_{n}=\frac{n \pi d}{L}$

For the galloping instability analysis, the external load is an aeroelastic load resulting from the interaction between the wind and the structure. Based on the quasi-stead assumption, this load is expressed in terms of the structural velocity.

Adopting quasi-steady theory, ignoring any nonlinear and torsional terms and assuming that there are in total $N$ modes in the $\alpha$-plane, where $\alpha=x, y$, contributing to the structural response, the nth modal loads for wind normal to the cable axis are given by [17]:

$$
\left\{\begin{array}{l}
f_{n, x}(t) \\
f_{n, y}(t)
\end{array}\right\}=-\frac{1}{2} \rho \int_{0}^{L} U(z) b(z)\left[\begin{array}{cc}
\phi_{n, x}(z) & 0 \\
0 & \phi_{n, y}(z)
\end{array}\right] \mathbf{C}_{a}(z) \Psi(z) \dot{\mathbf{P}}(t) d z
$$

where $U(z)$ and $b(z)$ are the density of air, mean wind velocity and reference width of the cross section of the cable, respectively, and:

$$
\begin{gathered}
\boldsymbol{\Psi}(z)=\left[\begin{array}{cc}
\boldsymbol{\Psi}_{x}(z) & \mathbf{0}_{2 N} \\
\mathbf{0}_{2 N} & \boldsymbol{\Psi}_{y}(z)
\end{array}\right] \text { and } \mathbf{O}_{N}=\left[\begin{array}{llll}
0 & 0 & \ldots & 0
\end{array}\right]_{1 \times N} \\
\boldsymbol{\Psi}_{\alpha}(z)=\left[\begin{array}{lllll}
\boldsymbol{\Phi}_{\alpha}(z) & \overline{\boldsymbol{\Phi}}_{\alpha}(z)
\end{array}\right] \text { and } \boldsymbol{\Phi}_{\alpha}(z)=\left[\begin{array}{lllll}
\phi_{1, \alpha}(z) & \phi_{2, \alpha}(z) & \ldots & \phi_{N, \alpha}(z)
\end{array}\right] \\
\mathbf{P}(t)=\left[\begin{array}{llllll}
\mathbf{P}_{x}(t) & \overline{\mathbf{P}}_{x}(t) & \mathbf{P}_{y}(t) & \overline{\mathbf{P}}_{y}(t)
\end{array}\right] \text { and } \mathbf{P}_{\alpha}(t)=\left[\begin{array}{llll}
p_{1, \alpha}(z) & p_{2, \alpha}(z) & \ldots & p_{N, \alpha}(z)
\end{array}\right]
\end{gathered}
$$




$$
\mathbf{C}_{a}(z)=\mathbf{R}^{T} \mathbf{C}_{a 0}(z) \mathbf{R} \text { and } \boldsymbol{R}=\left[\begin{array}{cc}
\cos \gamma & \sin \gamma \\
-\sin \gamma & \cos \gamma
\end{array}\right] \text { and } \mathbf{C}_{a 0}(z)=\left[\begin{array}{cc}
2 C_{d}(z) & C_{d}^{\prime}(z)-C_{l}(z) \\
2 C_{l}(z) & C_{d}(z)+C_{l}^{\prime}(z
\end{array}\right]
$$

in which $\gamma$ is the angle between the wind and the axis $y ; C_{d}$ and $C_{l}$ are the drag and lift coefficients; $C_{d}^{\prime}$ and $C_{l}^{\prime}$ are their derivatives with respect to the angle of attack, i.e. the angle between the wind and a reference line on the cross section.

In Eqs. (10)-(14), the subscript $\alpha$ stands for the $\alpha$-plane. This notation is used from now on.

In general, the aerodynamic coefficient matrix $\mathbf{C}_{a 0}$ is full. Therefore the modal aeroelastic loads given in Eqs.(10) involve aeroelastic coupling between translational motions in the $x$ and $y$ direction.

To formulate the galloping analysis problem, substituting Eqs. (10) into Eqs. (6) and arranging the obtained equations in matrix form [17]:

where

$$
\mathbf{A P}(t)+\mathbf{B} \dot{\mathbf{P}}(t)=\mathbf{0}
$$

$$
\begin{gathered}
\mathbf{A}=\operatorname{diag}\left[\begin{array}{llllll}
\mathbf{A}_{x} & \overline{\mathbf{A}}_{x} & \mathbf{A}_{y} & \overline{\mathbf{A}}_{y}
\end{array}\right] \text { and } \mathbf{A}_{\alpha}=-\left[\begin{array}{llll}
\lambda_{1, \alpha} w_{1, \alpha} & \lambda_{2, \alpha} w_{2, \alpha} & \ldots & \lambda_{N, \alpha} w_{N, \alpha}
\end{array}\right] \\
\mathbf{B}=\mathbf{W}+\tilde{\mathbf{C}}_{\alpha} \\
\mathbf{W}=\operatorname{diag}\left[\begin{array}{lllll}
\mathbf{W}_{x} & \overline{\mathbf{W}}_{x} & \mathbf{W}_{y} & \overline{\mathbf{W}}_{y}
\end{array}\right] \text { and } \mathbf{W}_{\alpha}=\operatorname{diag}\left[\begin{array}{llll}
w_{1, \alpha} & w_{2, \alpha} & \ldots & w_{N, \alpha}
\end{array}\right] \\
\widetilde{\mathbf{C}}_{\alpha}=\frac{1}{2} \rho \int_{0}^{\mathrm{L}} U(z) b(z) \Psi^{\mathrm{T}}(z) \mathbf{C}_{a}(z) \boldsymbol{\Psi}(z) \mathrm{dz}
\end{gathered}
$$

Galloping occurs, i.e. the system is unstable, if there exists an eigenvalue of Eq.(15), denoted as $\Lambda$, such that its real part, $\operatorname{Re}(\Lambda)$, is positive. The mean wind velocity at which $\operatorname{Re}(\Lambda)$ is zero is referred to as the critical wind velocity. The meaning of the critical wind velocity is that when it is lower than the mean wind velocity, the structure will gallop. Conventionally, the critical velocity is as a constant value. However, for non-horizontal structures, the variation of mean wind velocity along the structure, governed by the mean wind profile, contributes to the eigenvalues of Eq.(15). It is therefore necessary to use a critical wind profile, which first introduced in [16], as:

$$
U_{c r}(z)=U_{c r}\left(z_{e}\right) \mu(z)
$$

where $z_{e}$ is a suitable reference height (not chosen in close proximity to the ground); $U_{c r}\left(z_{e}\right)$ is the critical wind velocity at ze, and $\mu(z)$ is a non-dimensional function expressing the shape of the mean wind velocity profile, e.g. a power or logarithmic law.

\section{APPLICATION}

As an example, a taut bridge cable with an attached viscous damper in the $y$-plane (in-plane) is considered, as in [4] in which the parameters are $L=215.11 \mathrm{~m}, b=0.2 \mathrm{~m}, a / L=0.08, T=3.96 \times 106 \mathrm{~N}, m=98.6$ $\mathrm{kg} / \mathrm{m}$. The cable is assumed to be inclined at $20^{\circ}$ with respect to the horizontal plane. The bridge is located in terrain characterized by a roughness length $z_{0}=0.3 \mathrm{~m}$. It is assumed that the mean wind velocity profile follows the logarithmic rule and the reference height is $z_{e}=10 \mathrm{~m}$ above the ground.

As the damper is very near the cable anchorage, the natural frequencies of the damper-cable system can be taken as in Eq.(9). In addition, assuming that the damper is optimised for the first mode of cable vibration, the optimised damping ratio for that mode is approximately $\xi_{\text {opt }}=\frac{\alpha}{2 L}$, [5-6].

In the presence of the damper, the modes in the y-plane are complex. Fig. 2 shows the real and imaginary parts of first two mode shapes in that plane. The mode shapes are normalised such that their values at the damper location are unity. It can be seen that due to the damper attached to the cable, there are kinks in the imaginary parts of the mode shapes. The modes in the $x$-plane (out-of-plane), in which no damper is attached, are real. The mode shapes are sinusoidal and are the same as the real part of the corresponding modes shapes in the y-plane (the solid lines).

To investigate the galloping behaviour when the damper is attached to the cable, the aerodynamic coefficients for an ice-accreted cable are taken from wind tunnel tests in[19] are employed, in which $C_{d}=$ 
$0.86, C_{l}=-0.11, C_{d}^{\prime}=-1.24, C_{l}^{\prime}=-2.77$ at zero angle of attack. The mass of the ice is assumed to be negligible, relative to the mass of the cable.
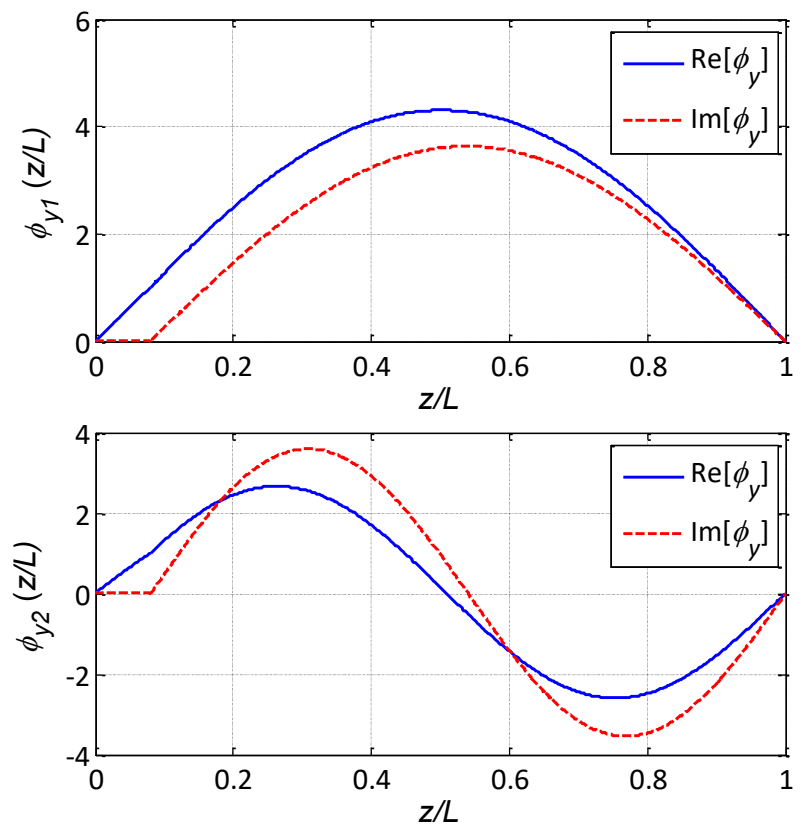

Figure 2. First and second mode in the $y$-plane for a cable with an attached damper at $a / L=0.08$.

As mentioned in Section 3, to identify the significance of different effects, it is useful to compare the rigorous solutions, allowing for complex modes, with those obtained from simplified analyses, without the damper and/or without the coupling between the two planes. For this purpose, four cases are considered:

(1) With the presence of the damper and the coupling between the two planes. This case corresponds to the rigorous analysis;

(2) With the presence of the damper and without the coupling between the two planes, i.e. $x$-plane and $y$-plane are uncoupled. The galloping analysis can be then conducted by considering only the vibrations in the $y$-plane, i.e. by solving the eigenvalue problem in Eq. (15), eliminating all terms with the subscript $x$;

(3) Without the presence of the damper and with the coupling between the two planes. The condition for galloping occurrence is given in [12] and [15];

(4) Without the presence of the damper and without the coupling between the two planes. The galloping problem becomes a single mode problem corresponding to the first across-wind mode of the cable, along with Glauert-Den Hartog.

These case are named as "xy Coupled (w/ damper)", " $y$ Uncoupled (w/ damper)", "xy Coupled (w/o damper)" and " $y$ Uncoupled (w/o damper)", respectively.

Fig. 3 shows the maximum values of the real parts of the eigenvalues of the system versus the mean wind velocity at the reference height for each case. It should be noted that since a structural system is unstable if there is at least one eigenvalue with a positive real part, using only the maximum values of the real parts of the eigenvalues determines the stability of the system.

Looking at the cases of undamped cable, if the vibrations in the two planes are uncoupled, i.e. case (4), it can be seen that the maximum real parts of the eigenvalues (dashed line) are positive, implying that the structural system is unstable. This is because $C_{a, y}=C_{d}+C_{l}^{\prime}=-1.91<0$. If the coupling between the two planes is taken into account (2DOF perfectly tuned system), i.e. case (3), the maximum real parts of the eigenvalues (continuous line) are more positive. This shows that the coupling between the two cable planes makes the structure more unstable than neglecting it. In other words, neglecting such a coupling can overestimate the stability of the structure. For other values of the aerodynamic coefficients, including the coupling can inverse the stability of the system. 
When the damper is installed, the stability of the structure is clearly improved. If the coupling between the $\mathrm{x}$-plane and y-plane is neglected, i.e. case (2), for the chosen values, the structural system is still stable for wind velocities up to $62 \mathrm{~m} / \mathrm{s}$. However, the situation changes if the coupling between the two planes is considered (case (1)). In this case, the maximum real parts of the eigenvalues (continuous line) are positive, i.e. the structure is potentially unstable, for $\mathrm{U}\left(z_{e}\right) \geq 60 \mathrm{~m} / \mathrm{s}$. So disregarding the coupling between the two cable planes can overestimate the critical velocity for the occurrence of galloping. This observation highlights the importance of the coupling. Neglecting it can give rise to results unsafe to the structure.

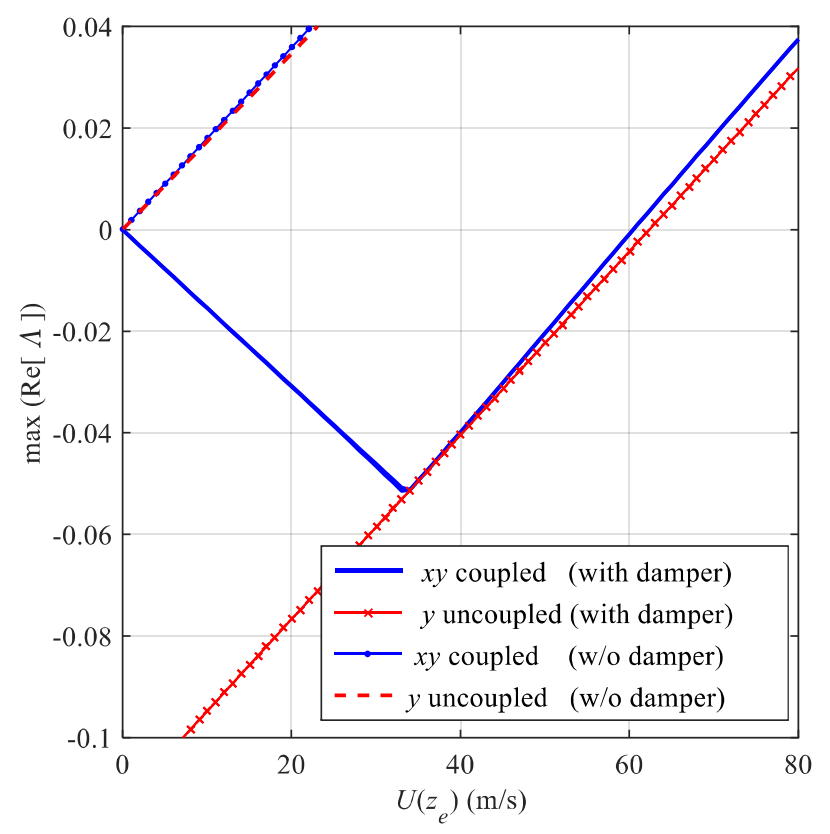

Figure 3. Maximum eigenvalues of the system.

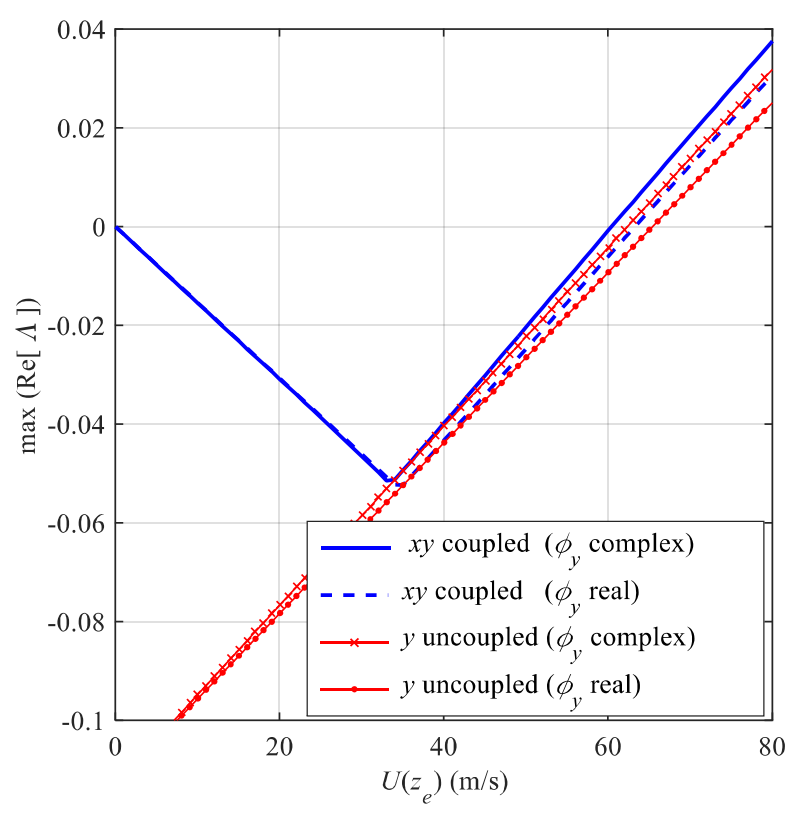

Figure 4. Comparison of maximum real part of eigenvalues with and without considering the complexity of the $y$-plane mode shapes. 
Fig. 4 shows the maximum values of the real parts of the eigenvalues of the cable-damper system with and without considering the complexity of the $y$-plane mode shapes $\phi_{y}(z)$. The analysis constitutes 4 cases, aiming to understand the role of the complex mode shapes, which have not been investigated previously in galloping analysis, to the authors' knowledge. First, the two planes are coupled and $\phi_{y}(z)$ are treated as complex. Second, the two planes are coupled and $\phi_{y}(z)$ are treated as real. Third, the two planes are uncoupled and $\phi_{y}(z)$ are treated as complex. Fourth, the two planes are uncoupled and $\phi_{y}(z)$ are treated as real. It should be noted that in all four cases, then damping of the modes in the y-plane is taken as in the presence of the damper. Strictly, the real mode shapes are not compatible with this but as the complexity of the mode shapes has not been considered before, the mode shapes have been considered as real.

It can be seen that, when the $y$-plane mode shapes $\phi_{y}(z)$ are treated as complex, the real parts of the eigenvalues are positive, i.e. the system is unstable, for $U\left(z_{e}\right) \geq 60 \mathrm{~m} / \mathrm{s}$ and for $U \geq 62 \mathrm{~m} / \mathrm{s}$ if the coupling between the two cable planes is considered (continuous line) and not considered (cross line), respectively. The results have already been shown in Fig. $3 \mathrm{a}$ and discussed above. On the other hand, if the imaginary parts of $\phi_{y}(z)$ are ignored, i.e. $\phi_{y}(z)$ treated as real, the predicted critical velocities increase, $63 \mathrm{~m} / \mathrm{s}$ with the coupling between the two planes (dash line) and $66 \mathrm{~m} / \mathrm{s}$ without the coupling (dot line). The observation shows the role of the complexity of the mode shapes. Ignoring them as in common galloping analysis can overestimate the critical velocity for the occurrence of galloping, which is unsafe for the structure.

\section{CONCLUSIONS}

This paper addresses previous limitation in conventional galloping analysis of stay cables with attached viscous damper, in which the complexity of mode shapes and frequencies is ignored. The conventional analysis is not accurate as complex modes shapes are involved due to the presence of the damper, which changes the model interactions. The paper therefore develops a general and rigorous framework to study the problem of galloping instability of a stay cable with two orthogonal attached viscous dampers, one in each principal cable plane. The complex mode shapes, the coupling between modes in the two planes of the cable and the variation of mass, width of cross-section, mean wind velocity and aerodynamic coefficients along the cable are taken into account. The analysis for the particular case that only one damper is attached to the cable is obtained by setting the damping coefficient associated with the undamped cable plane as zero.

Based on the aerodynamic data obtained from wind tunnel tests a stay cable accreted by ice, the numerical application of the proposed theory reveals several crucial points of engineering significance. Firstly, the stability analysis can be conducted based on only the first system mode predominantly in the across-wind plane. Secondly, the coupling between the in-plane and out-of-plane modes is particularly important. It is shown that the coupling may cause critical wind velocities considerably lower than if the coupling is ignored. Finally, the paper points out that neglecting the imaginary parts of the mode shapes overestimates critical wind velocities, providing unsafe prediction for the galloping occurrence.

\section{ACKNOWLEDGEMENT}

This research is financially support by the Industrial University of Ho Chi Minh City, grant No.171.1061. The authors are grateful for the support.

\section{REFERENCES}

[1] Carne, T. G. Guy Cable Design and Damping for Vertical Axis Wind Turbines. SAND80-2669, Sandia National Laboratories, Albuquerque, New Mexico, 1981.

[2] Yoneda, M. and Maeda, K. A Study on Practical Estimation Method for Structural Damping of Stay Cable with Damper. Proc. Canada-Japan Workshop on Bridge Aerodynamics, 119-128, 1989.

[3] Uno, K., Kitagawa, S., Tsutsumi, H., Inoue, A. and Nakaya, S. A Simple Method of Designing Cable Vibration Dampers of Cable-stayed Bridges. ASCE Journal of Structural Engineering, 37A, 789-798, 1991.

[4] Pacheco B.N., Fujino Y., and Sulekh A. Estimation curve for modal damping in stay cables with viscous damper, Journal of Structural Engineering119, 1961-1979, 1993. 
[5] Krenk S. Vibrations of a taut cable with an external damper, Journal of Applied Mechanics67772-776, 2000.

[6] Main, J.A., and Jones, N.P. Free vibrations of taut cable with attached damper. I: Linear viscous damper, Journal of Engineering Mechanics, 128, 1062-1071, 2002.

[7] Caetano E. Cable vibrations in cable-stayed bridges, Structural Engineering Documents, Vol. 9, IABSE, Zurich, Switzerland, 2007.

[8] Fujino Y., Kimura K., and Tanaka H. Wind Resistant Design of Bridges in Japan, Springer, Japan, 2012.

[9] Glauert, H. The rotation of an aerofoil about a fixed axis. British Advisory Committee for Aeronautics (ARC) $R$ \& M No. 595. Technical Report of ARC for 1918-1919, 443-447, 1919.

[10] Den Hartog, J.P, Transmission line vibration due to sleet, T. Am. Inst. El. Eng., 51, 1074-1076, 1932.

[11] Macdonald and Larose. A unified approach to aerodynamic damping and drag/lift instabilities, and its application to dry inclined cable galloping. Journal of Fluids and Structures 22 (2), 229-252, 2006.

[12] Jones K.F. Coupled vertical and horizontal galloping, Journal of Engineering Mechanics, 118 (1), 92-107, 1992.

[13] Luongo, A., Piccardo, G. Linear instability mechanisms for coupled translational galloping. Journal of Sound and Vibration 288, 1027-1047, 2005.

[14] Carassale, L., Freda, A., and Piccardo, G. Aeroelastic forces on yawed circular cylinders quasi-steady modelling and aerodynamic instability. Wind and Structures. 8(5), 373-388, 2005.

[15] Macdonald, J.H.G., and Larose, G. Two-degree-of-freedom inclined cable galloping. Part1: general formulation and solution for perfectly tuned system. Journal of Wind Engineering and Industrial Aerodynamics 96, 291$307,2008$.

[16] Nguyen, C.H., Freda, A., Solari, G. and Tubino, F., Aeroelastic instability and wind-excited response of complex lighting poles and antenna masts, Eng. Struct., 85, 264-276, 2015.

[17] Nguyen C.H, Macdonald. J.H.G. "Galloping analysis of a stay cable with attached viscous damper considering complex modes". ASCE Journal of Engineering Mechanics (Accepted).

[18] Hurty W.C. and Rubinstein M.F.,. Dynamics of Structures, Prentice-Hall, Englewood Cliffs, New Jersey, 1964.

[19] Gjelstrup, H., Georgakis, C.T., and Larsen, A. An evaluation of iced bridge hanger vibrations through wind tunnel testing and quasi-steady theory. Wind and Structures, An International Journal, 15 (5), pp. 385-407, 2012.

\section{PHÂN TÍCH HIỆN TỰ̛̣ng BẤT ỔN ĐỊNH GALLOPING CỦA HỆ CÁP DÂY VĂNG CÓ GẮN GIẢM CHẤN}

Tóm tắt. Việc sử dụng hệ cản nhớt để giảm dao động của cáp dây văng là rất phổ biến. Một bộ cản được gắn vào cáp dây sẽ dẫn đến các mode dưới dạng phức. Tính phức này sẽ ảnh hưởng lớn đến tính ổn định khí động học của cáp. Phân tích bất ổn định galloping của cáp có gắn hệ cản sẽ được giới thiệu trong bài báo này. Một ví dụ số chỉ ra những sai số của phương pháp phân tích truyền thống. Tính phức của các dạng mode sẽ gây ra bất ổn định nhiều hơn so với khi xem chúng là các mode thực.

Từ khóa. cáp, cáp cầu dây văng, mặt cắt phức tạp, galloping, giảm chấn nhớt.

Ngày nhận bài: 29/09/2017

Ngày chấp nhận đăng: 31/12/2017 